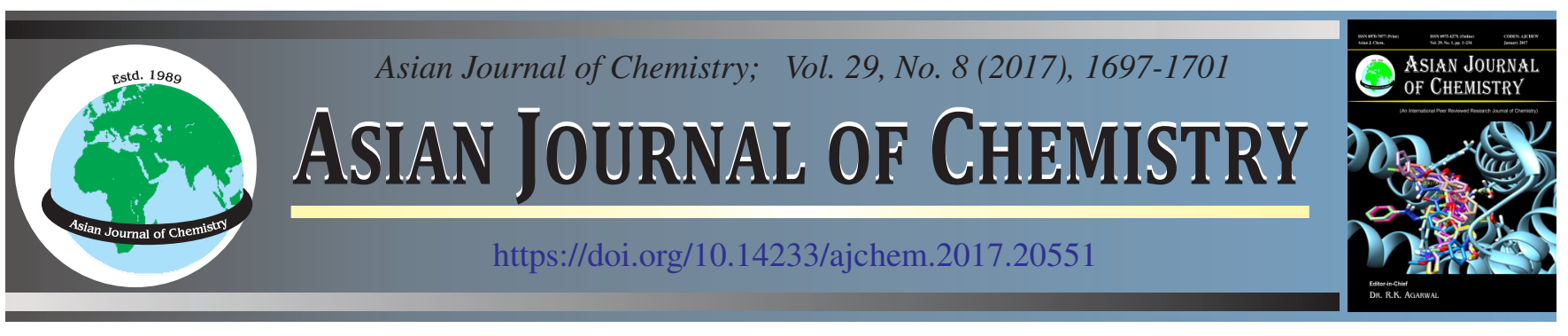

\title{
Effect of Filler on Mechanical Properties of Natural Fiber Reinforced Composites
}

\author{
K.P. ASHIK ${ }^{1, *}$, RAMESH S. SHARMA ${ }^{1}$ and N. RAGHAVENDRA ${ }^{2}$
}

${ }^{1}$ Department of Mechanical Engineering, R.V. College of Engineering, Bengaluru-560 059, India

${ }^{2}$ Centre for Manufacturing Research \& Technology Utilization (CMRTU), R.V. College Campus, Bengaluru-560 059, India

*Corresponding author: E-mail: ashikkallare@gmail.com

Received: 30 January 2017;

Accepted: 12 April 2017;

Published online: 12 June 2017;

AJC-18424

\begin{abstract}
Natural fiber reinforced composites are progressively used in a variety of commercial applications such as automotive, aerospace and marine. Many technologies demand materials with unusual mixture of properties such as high strength to weight ratio, high stiffness, high corrosion resistance, high fatigue strength, high dimensional stability, etc. These can't be met by conventional metal alloys, due to comparable properties the scope of for natural fibers became enormous. More research work is done on natural fiber composites. But, woven jute fiber and epoxy resin matrix is not used for research studies. Literature review shows that composite made of combination of these constituents is not studied in order to know its properties. Present study focus on the effect of nano silicon dioxide as filler on tensile, flexural and fatigue properties of jute reinforced epoxy composites with three different combinations of filler material and two different orientations. The three different compositions were $0 \%$ nano silicon dioxide, $5 \%$ nano silicon dioxide, $10 \%$ nano silicon dioxide. The two different orientations were $0 / 90$ and $+45 /-45$ orientation. Tensile and flexural strength of all the compositions of the composites reveled that ultimate tensile strength, peak load and young's modulus were more in case of $5 \%$ silica filled jute epoxy composite compared to other two compositions. Similarly fatigue test to determine the number of cycles up to $50 \%$ stiffness degradation of laminates reveals that specimens loaded with $5 \%$ nano silicon dioxide shows higher number of cycles. The study concludes that the combination of filler and fiber composite material is competitive to synthetic composites.
\end{abstract}

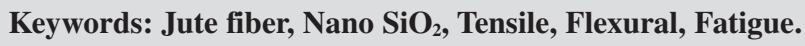

\section{INTRODUCTION}

In recent past years, the concept of natural resources has gained key importance due to the necessity to preserve our natural environment. These nature friendly materials are also termed as "eco-materials" or "bio materials". The meaning of eco-material is 'safe' material systems for human and other life forms at all times. From the past experience, it is necessary for us to qualify the materials and settle those which are safe for both short and long-term employment. Selection of a material should be like that it not only satisfies industrial requirements but also meets the wider definition of eco-materials, as described above, is a present necessity for us [1]. Here, the most appropriate concept for material selection is composite materials with natural fiber reinforcement. The involvement of natural fiber reinforced composites is growing at a faster rate both in terms of their industrial works and research works also. The accessibility, renewability, low density and less price as well as satisfactory mechanical properties of the natural fiber reinforcement's composites make them a pleasing ecological alternative to glass, carbon and other man-made fibers or synthetic fibers used for the processing of composites structures. The natural fiber reinforced composites are more environmental friendly and are widely used for manufacturing automobiles parts, railway coaches, aerospace, military applications, building and in construction industries for making ceiling paneling, partition boards, packaging, consumer products etc. Ferreira et al. [2] had studied the fatigue behaviour of bidirectional woven cloth mixture of E-glass fibers and polypropylene fibers thermoplastic composites. They studied for fiber volume distribution and strain rate of laminated composites with change in lay-up orientation. Belkacemi and Bezzazi [3] determined the quasi-static mechanical property and fatigue property of a jute fiber reinforced polyester composite laminates. Laminates were arranged in a stacking sequence of $0^{\circ} / 90^{\circ}$ for both tensile test and fatigue test. Tensile test shows a linear proportion up to $20 \mathrm{MPa}$ and a non-linear portion to rupture at stress max of $47 \mathrm{MPa}$ followed by elongation of $2.08 \%$ with a break elongation of $2.50 \%$. They also revealed that increment in loading decreases the number of cycles to failure. They also concluded that the fatigue behaviour generally depends upon the nature of fiber, resin and the interface between them. 
Vasconcellous et al. [4] determined the effect of sequence on the mechanical properties of woven hemp fiber reinforced with epoxy resin laminated composites. The sequence of stacking were $\left(0^{\circ} / 90^{\circ}\right)$ and $\left(+45^{\circ} /-45^{\circ}\right)$. The tension-tension fatigue tests were performed on different specimens until it ruptures and later the damaged specimens were observed under combined techniques like optical microscope and X-ray micro topography, measurements of temperature fields with the help of infrared cameras and acoustic emission monitoring. The results obtained by them provides a complete description about the fatigue damage mechanisms and also a better damage scenario occurred throughout the fatigue tests. Amuthakkannan et al. [5] had investigated the effect of length of fiber and percentage variation of short basalt fiber on the mechanical properties. Specimens with different fiber length and fiber content are subjected to tensile test, flexural test and impact strength test and later the damaged composite laminates were examined with the help of scanning electron microscope. Hossain et al. [6] had studied about the longitudinal tensile strength of jute fiber reinforced with epoxy resin composites laminates. Laminates were having different jute fiber stacking sequence $(0 / 0 / 0),(0 /+45 /-45 / 0)$ and $(0 / 90 / 90 / 0)$. Further, it was determined that the tensile strength of jute fibers plays a very important role in providing the tensile strength property of the composites. Abilash and Sivapragash [7] studied on jute fiber and found it to be a better and major material for application in rural areas for high tech applications. These fibers are bio degradable and thus environmental friendly, the energy consumptions is also reduced which is required for manufacturing of synthetic fibers. It is also coated that more research has to be carried out on the natural fibers to avoid any setbacks during the finalization from lab scale to commercial level. Bharath et al. [8] had studied the tensile and moisture absorption property of randomly distributed areca fiber packed along with fine maize powder reinforced urea formaldehyde composites. Composites were manufactured first and then pressed by using a hydraulic hot press maintained at $150{ }^{\circ} \mathrm{C}$. All the tests were conducted according as per the ASTM standards. The tensile tests were conducted to determine the tensile strength and moisture absorption test were conducted to study the moisture absorption resistance property of composites. Makeev et al. [9] generated S-N curves based on the shear fatigue tests performed on costumed short beam. The custom short beams test configuration ensure a consistent inter-laminar shear failure mode. The tested data sets that are used to develop the fatigue properties include 20 glass fiber reinforced with epoxy and 30 carbon fiber reinforced with epoxy components. All the tests were performed under control loading rate of 0.1 load ratio for better understanding of material behaviour under cyclic loading. Jansons et al. [10] evaluated the effect of moisture and temperature as well as fatigue properties of carbon fiber reinforced polymer composites. From the study reveals that moisture absorption depends on the thickness of the laminate and properties also depends on the thickness of the composite. Unigovski et al. [11] studied the effects of thermal cycling on low-cycle fatigue behaviour of carbon-epoxy laminate in a purely bending mode having strain ratio variation of -1 and 0.1 . It was determined that with a small increase in the plastic strain amplitude the fatigue life $\mathrm{N}$ of the composite is decreased as determined by the number of cycles corresponding to initial force of 0.9 . The initial thermal cycling of the composite was done by varying the temperature from $180{ }^{\circ} \mathrm{C}$ to $-195.8^{\circ} \mathrm{C}$ which shortens the number of cycle's values in comparison to the reference at small strains. From the literature survey tensile strength and Young's Modulus of jute are lower than those of glass fiber, the specific modulus of jute fiber is superior to that of glass. Jute can be partially or fully replace for glass in a higher strength and stiffness than glass gives benefit to design parts for bending stiffness due to its lower specific gravity and higher specific modulus.

\section{EXPERIMENTAL}

Manufacturing of composites plates were carried out using jute fibers, epoxy (LY 556) resin and silica powder as filler. Woven Jute fibers were obtained from M/s Jute Creations, Bengaluru. Silicon di oxide of 90 microns (particle size) was obtained from M/s. Loba Chemie Pvt. Ltd. Epoxy resin and K-5 (HT-972) hardener was obtained from GRP pultrusions, Bengaluru.

Fabrication: The composite materials used for the present investigation was manufactured by using hand lay-up process [12]. Initially jute fiber was placed under the weighted tiles in order to remove the folding's of the fibers.Jute fibers were then allowed to dry in sun light to remove the moisture content in fibers. The surface plate was kept on the table that acts as a base for the preparation of composite laminates. The Mylar sheet was placed on the surface plate and clamped at its end by means of clamping pins. The required fiber was placed over the Mylar sheet carefully without any shrinkage and blowholes. Keeping one side on the table resin and hardener mixture ready and poured the resin uniformly over the required fiber by means of brush. Then rolling and leveling was done on the layers of fibers to achieve high bonding strength, uniform resin distribution and to remove bubbles. Depending upon the thickness of the laminates required layer of fibers are stacked. Another Mylar sheet was placed above the laminates and allowed for room temperature curing. Finally the specimens were kept in the hydraulic press of capacity $30 \mathrm{Kg} / \mathrm{cm}^{3}$ to press the laminates by removing the entrapped air gap between the stacking layers of fiber and resin. After pressing, then laminates were removed from the hydraulic press and then laminates were cut into required dimension followed by removing the uneven surfaces. Similarly other two different laminates with filler variation $(5 \%, 10 \%)$ were prepared.

\section{Characterization}

Tensile test: Tensile test or tension test is a basic test in which a specimen is subjected to uniaxial tension until the material fractures uniaxial tension refers to the force acting on the opposite faces of the material in opposite direction with respect to each other along the same axis. The material is placed between two grips and is subjected to tensile or tension force. This force causes the gauge length of the material to elongate and finally material fractures. Thus, elongation, final cross sectional area and peak load of the material are obtained directly from tensile test. In the present investigation tensile 
test carried out by using ASTM D 638 test standard. The specimen size as per ASTM standard D 638 is $165 \mathrm{~mm}$ length, $19 \mathrm{~mm}$ width and $3 \mathrm{~mm}$ thickness. The specimen looks similar to dumbbell. The specimens were cut using small toothed table saw and the burrs were removed with the help of very smooth emery paper grade 1000 and the specimens were cleaned.

Flexural test: Flexural test is to determine the competency of a material to withstand bending force before reaching to the breaking point. The main advantage of a three point flexural test is the simplicity of the specimen preparation and testing. This method even have some disadvantage also such as the results of the testing method are sensitive to specimen and loading geometry and strain rate. In the present investigation flexural test carried out using ASTM D 790 standard. This is one of the most commonly and widely used specification in the composite industry. The specimen size as per ASTM standard D 790 is $127 \mathrm{~mm}$ length, $12.7 \mathrm{~mm}$ width and $3 \mathrm{~mm}$ thickness. The span to depth ratio was 16:1. For each specimen, the maximum loads were determined from the data logger. Maximum load and the maximum flexural stress for each specimen were calculated by using the relationship.

Fatigue test: In terms of engineering most of the materials fails due to fatigue loading. Failure due to fatigue is defined as the tendency of a material to fails or rupture under repeated cyclic loading and alternating stress of an intensity which is comparatively lower than the normal strength of the material. Mainly the fracture is of brittle type as it may take time to propagate. The crack propagation in a material depends upon the intensity of loading or the variation stresses to cause fatigue failure. Fatigue failure particularly depends upon the peak stress. The peak value is normally quite large but it tends to decreases as the stress are induced more. In the present investigation fatigue test was carried out using ASTM D 7774. The fatigue tests were performed under a displacement controlled sinusoidal cycle using a computerized servo hydraulic testing machine having a capacity of $50 \mathrm{KN}$ and length accuracy of $+/-0.05 \mathrm{~mm}$, load accuracy $+/-0.5 \%$ of reading, Load resolution of at least 1 in 10000 parts, actuator stroke $50 \mathrm{~mm} /$ $100 \mathrm{~mm} / 250 \mathrm{~mm}$.

\section{RESULTS AND DISCUSSION}

Tensile properties: In the investigation tensile test was carried out by put on tensile load on the tensile specimen. In every test, three specimens were tested to achieve average values of same composition of specimen and results were noted. The laminate was fixed in the fixture of the machine and load was applied and the corresponding change in length of the specimen was recorded. The load was applied on the laminate until it breaks and peak load, ultimate tensile strengths were recorded. After testing stress and strain curve obtained from the software it was recorded and load $v s$. displacement graphs were generated.

Fig. 1 shows the tensile strength variation with different filler loading percentage along with different fiber orientation. Finally results note that overall $5 \%$ silicon dioxide loaded specimen exhibits higher tensile strength as compared to the other two combinations of filler loading.

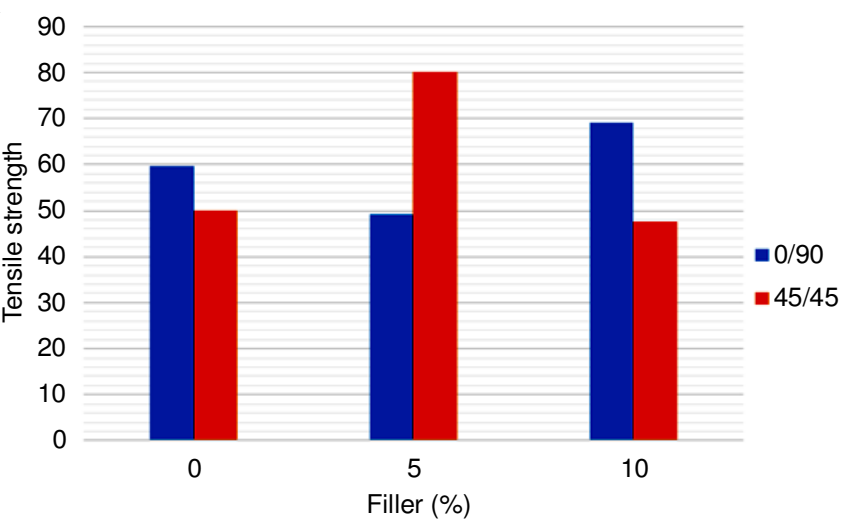

Fig. 1. Variation of tensile strength for different filler loading percentage of specimen

Flexural properties: The investigation flexural test was carried by put on load in between the test length of the specimen. In every test, three specimens were tested to achieve average values of same composition of specimen and results were noted. Test carried on the different filler loading percentage of specimen and the various parameters of flexural testing was determined. Peak load was recorded and load $v$ s. displacement graphs were generated.

Fig. 2 shows the flexural strength variation in different filler loading and with variation of fiber orientation. All the specimens are treated at normal room temperature. It exhibits the higher flexural strength in $5 \%$ silicon dioxide filler loaded specimen as compared to the other two combinations are 0 and $10 \%$ silicon dioxide loaded specimens. And also the comparing both the orientations of all combinations of filler loading, we observed that for $5 \%$ silicon dioxide for both the orientation shows greater flexural strength

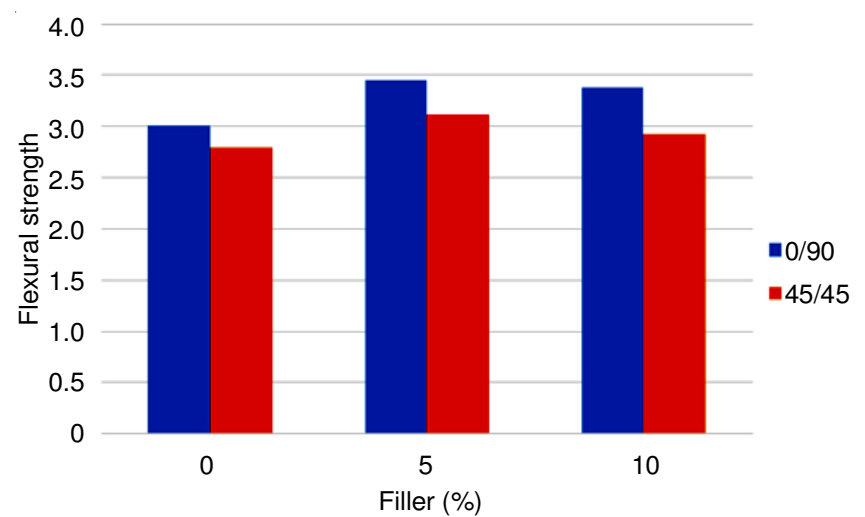

Fig. 2. Variation of flexural strength for different filler loading percentage of specimen

Flexural fatigue properties: Investigation of fatigue test carried according to the ASTM standards, the dimension of the test specimen was $135 \mathrm{~mm}$ length, $12.7 \mathrm{~mm}$ width and thickness of $3 \mathrm{~mm}$. The fatigue test frequency test was maintained in between 5 to $7 \mathrm{~Hz}$. The test was controlled by allowing displacement and load to vary. The variation of the load needs to be closely monitored. The tests were performed to a maximum of $10^{3}$ cycles. The machine was set to stop automatically if the loading is decreased to a value of $50 \%$ of the flexural strength or stiffness degradation. Maintained a constant deflection of 
$2 \mathrm{~mm}$ manually by tuner provided in the ends. Enabled the machine and command start from the computer simultaneously adjusted the maximum load required for the specimen. Adjusted the amplitude manually by looking into the software followed by having the constant frequency. Table-1 represent the peak loads obtained for the different filler loading percentage of specimen.

\begin{tabular}{|c|c|c|}
\hline \multicolumn{3}{|c|}{$\begin{array}{l}\text { TABLE-1 } \\
\text { PEAK LOAD OBTAINED FOR THE DIFFERENT } \\
\text { FILLER LOADING PERCENTAGE OF SPECIMEN }\end{array}$} \\
\hline \multicolumn{2}{|c|}{ Specimen identity } & Peal load $(\mathrm{N})$ \\
\hline \multirow{2}{*}{$0 \%$} & $0^{\circ} / 90^{\circ}$ & 117.61 \\
\hline & $+45^{\circ} /-45^{\circ}$ & 107.83 \\
\hline \multirow{2}{*}{$5 \%$} & $0^{\circ} / 90^{\circ}$ & 147.24 \\
\hline & $+45^{\circ} /-45^{\circ}$ & 127.68 \\
\hline \multirow{2}{*}{$10 \%$} & $0^{\circ} / 90^{\circ}$ & 137.32 \\
\hline & $+45^{\circ} /-45^{\circ}$ & 117.59 \\
\hline
\end{tabular}

Figs. 3-5 indicated the stress vs. number of cycle plots of different filler loading percentage of specimen obtained from the testing machine. Fig. 3 indicates the sample graph generated from the machine for stress $v s$. number of cycles for fatigue test of $0 \% \mathrm{SiO}_{2}$ specimen. Fig. 4 indicates the sample graph generated from the machine for stress $v s$. number of cycles for fatigue test of $5 \% \mathrm{SiO}_{2}$ specimen similarly Fig. 5 indicates the sample graph generated from the machine for stress vs. number of cycles for fatigue test of $10 \% \mathrm{SiO}_{2}$ specimen.

Residual strength: Flexural test on the fatigue tested specimen was again performed in order to determine the residual strength of the specimens after $10^{3}$ number of cycles and with a $50 \%$ reduction in the stiffness value.

Damage index of different filler loading percentage of specimen were calculated using eqn. 1. Damage index depends on the flexural strength of the specimen. Table- 2 indicates the

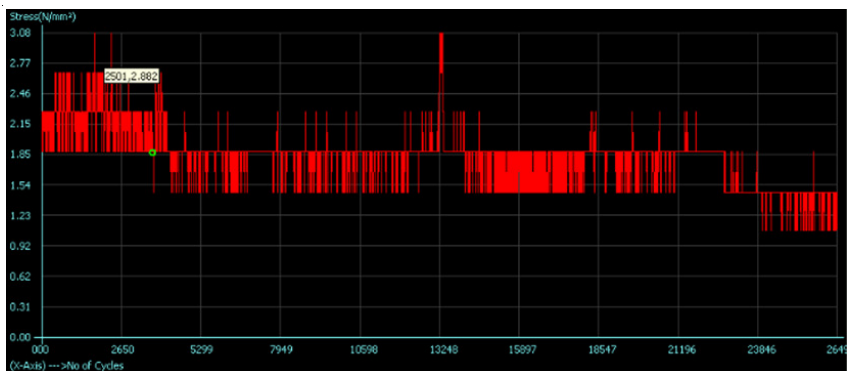

Fig. 3. Sample graph generated from the machine for stress $v s$. number of cycles for fatigue test of $0 \% \mathrm{SiO}_{2}$ specimen

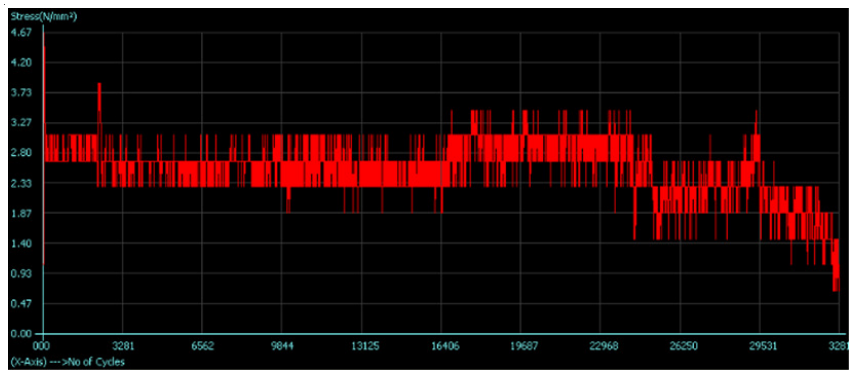

Fig. 4. Sample graph generated from the machine for stress $v s$. number of cycles for fatigue test of $5 \% \mathrm{SiO}_{2}$ specimen

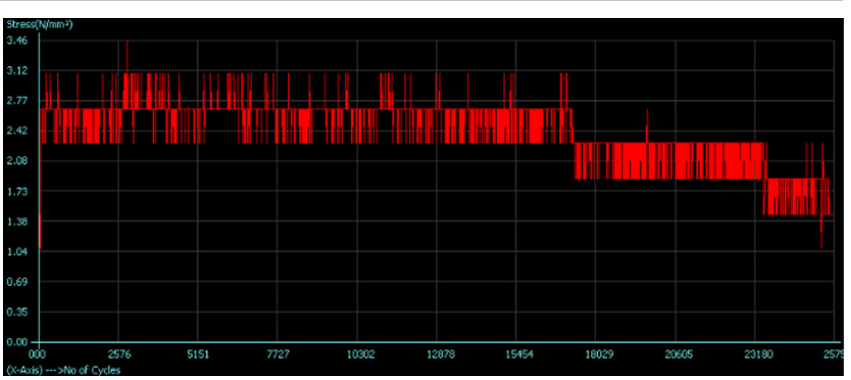

Fig. 5. Sample graph generated from the machine for stress $v s$. number of cycles for fatigue test of $10 \% \mathrm{SiO}_{2}$ specimen

\begin{tabular}{ccc}
\multicolumn{2}{c}{ TABLE-2 } \\
DAMAGE INDEX VARIATIONS OF DIFFERENT \\
FILLER LOADING PERCENTAGE OF SPECIMEN \\
\hline \multicolumn{2}{c}{ Specimen identity } & Damage index \\
\hline \multirow{2}{*}{$0 \%$} & $0^{\circ} / 90^{\circ}$ & 0.17 \\
& $+45^{\circ} /-45^{\circ}$ & 0.17 \\
\hline \multirow{2}{*}{$5 \%$} & $0^{\circ} / 90^{\circ}$ & 0.19 \\
& $+45^{\circ} / 45^{\circ}$ & 0.15 \\
\hline \multirow{2}{*}{$10 \%$} & $0^{\circ} / 90^{\circ}$ & 0.16 \\
& $+45^{\circ} /-45^{\circ}$ & 10.11 \\
\hline
\end{tabular}

damage index variation of different filler loading percentage of specimen. Fig. 6 indicates the variation of damage index of different filler loading percentage of specimen.

$$
\text { Damage index }=1-\frac{\text { Residual strength }}{\text { Flexural strength }}
$$

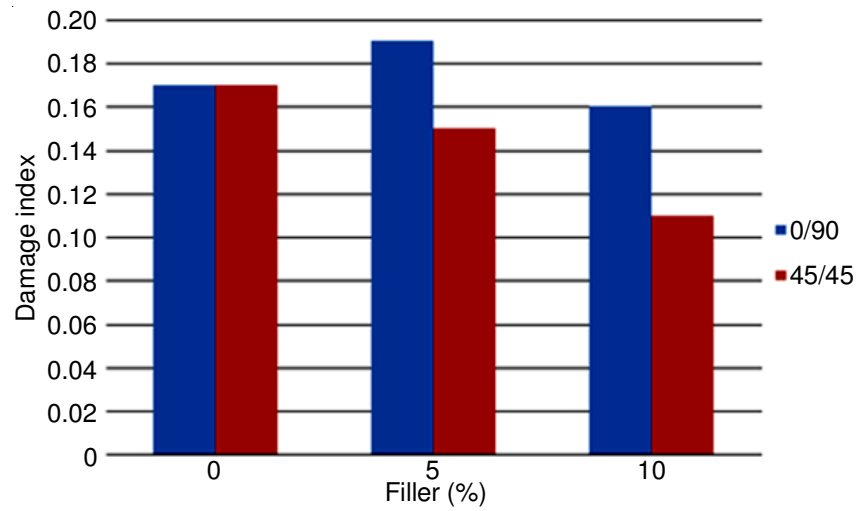

Fig. 6. Indicate the variation of damage index of different filler loading percentage of specimen

\section{Conclusion}

The fabrication and experiments on jute epoxy laminates are conducted efficiently and all the results are tabulated and discussed. The three different compositions were $0 \%$ nano silicon dioxide, $5 \%$ nano silicon dioxide, $10 \%$ nano silicon dioxide. The two different orientation were $0 / 90$ and $+45 /-45$ orientation.

- Tensile tests on all of different filler loading percentage of specimenreveled that ultimate tensile strength, peak load and young's modulus were more in case of $5 \%$ silica filled jute epoxy composite compared to other two compositions and $(+45 /-45)$ orientation gives good tensile strength. Hence result conclude that $5 \%$ of nano silicon dioxide as filler has good tensile properties. Tensile properties reduce for jute epoxy composite with $10 \%$ silica as filler material. By the addition 
of $10 \%$ silica bonding strength of the epoxy may have reduced due to lesser weight percentage of epoxy.

- Flexural test or 3 point bend test results reveal that $5 \%$ of nano silicon dioxide gives better flexural strength when compared to other two combinations. Here in this case $(0 / 90)$ orientation shows better flexural strength as compared to $(+45 /$ $-45)$ orientation.

- Flexural fatigue test to determine the number of cycles up to $50 \%$ stiffness degradation of laminates reveals that specimens loaded with $5 \%$ nano silicon dioxide withstand higher number of cycles and showed better result compared to other two compositions.

\section{REFERENCES}

1. K.P. Ashik and R.S. Sharma, J. Miner. Mater. Charact. Eng., 3, 420 (2015); https://doi.org/10.4236/jmmce.2015.35044.

2. J.A.M. Ferreira, J.D.M. Costa and P.N.B. Reis, Theor. Appl. Fract. Mech., 31, 67 (1999); https://doi.org/10.1016/S0167-8442(98)00068-8.
3. C. Belkacemi and B. Bezzazi, Adv. Appl. Sci. Res., 5, 328 (2014).

4. D. Vasconcellos, F. Touchard and L. Chocinski-Arnault, in Proceedings of 15 th European Conference on Composite Materials, Venice, Italy June (2012).

5. P. Amuthakkannan, V. Manikandan, J.T.W. Jappes and M. Uthayakumar, Mater. Phys. Mechanics, 16, 107 (2013).

6. M.R. Hossai, M.A. Islam, A. van Vuurea and I. Verpoest, Procedia Eng., 56, 782 (2013);

https://doi.org/10.1016/j.proeng.2013.03.196.

7. N. Abilash and M. Sivapragash, Eng. Sci. Technol.: An Int. J., 3, 7 (2013).

8. K.N. Bharath and R.P. Swamy, Int. J. Recent Trends Eng., 1, 60 (2009).

9. A. Makeev, C. Ignatius, Y. He and B. Shonkwiler, J. Compos. Mater, 43, 3091 (2009); https://doi.org/10.1177/0021998309345330.

10. J.O. Jansons, K. Glejbøl, J. Rytter, A.N. Aniskevich, A.K. Arnautov and V.L. Kulakov, Mech. Compos. Mater, 38, 299 (2002); https://doi.org/10.1023/A:1020024007414.

11. Ya.B. Unigovski, A. Grinberg, E.M. Gutman and R. Shneck, J. Metal Mater. Miner., 22, 21 (2012).

12. M.R. Sanjay, G.R. Arpitha, L.L. Naik, K. Gopalakrishna and B. Yogesha, J. Mater. Environ. Sci., 7, 3179 (2016). 